\title{
Obstacles to Managing Dynamic Systems. The Systems Thinking Approach
}

\author{
Adalberto Rangone, PhD \\ Adjunct Professor of Strategic Management \\ Department of Economics and Management \\ University of Pavia - Italy \\ Piero Mella \\ Professor of Control Theory \\ Department of Economics and Management \\ University of Pavia - Italy
}

\begin{abstract}
The world is a dynamic system composed of a system of dynamic systems of different sizes, nested at multiple levels and interfering with each other: environmental, social, political, economic systems, ecosystems, organizations, companies, groups,parties and interacting individuals. Systems Thinking is a methodological approach that offers tools for understanding and, most importantly, controllingdynamic systems of any kind in any field, building models to understand, simulate andabove all "control"the incessant movementsand continual transformations and evolution dynamic systems. In many situations, no matter how much time and energy managers dedicate to this task, the control of dynamic systems is not possible or is impeded by certain conditions that make it nearly "impossible to control" the dynamic world with all its dynamic processes and interconnections. By describing brief "metaphors", this study will present six of the conditions that make it "difficult, if not impossible, to perceive dynamics", thus impedingmanagersfrom "understanding" and "controlling" the world.Some processes are so slow that managersare not able to perceive their dynamics; by the time they become aware of their effects it is too late to control them, and we end up like a boiled frog (first metaphor). At other times, processes are so fast, explosive and exponential that by the time managersbecome aware of them there is no time to undertake any control (second metaphor ofthe water lilies). Some processes derive from the concatenation of many loops, which are contained in other loops. When, in a far-off land, a butterfly flutters its wings, it can unleash a chain of vortices which, gradually gaining in strength, can set off a storm in another part of the world (third metaphor). At times, some variables depend on the myopic behaviour of many agents who prefer to repeat behavior that produces short-term, individual and local advantages, thus ignoring the long-term, collective and global disadvantages such behavior inexorably produces (fourth metaphor). The monodirectional view(fifth metaphor) blocks managersfrom understanding the interactions and dynamics of events. Systems Thinking encounters an often-insurmountable obstacle in structural complexity of non-trivial dynamic systems (sixth metaphor).
\end{abstract}

Keywords: Systems Thinking, boiled frog, frozen frog, networking effect, butterfly effect, temporal myopia, monodirectional view, complexity of structure

\section{Introduction}

The term Systems Thinking - as proposed by Peter Senge in his major work entitled The Fifth Discipline (1990 first ed.; 2006 last ed.) -indicatesa way of thinking that observes "systems" in all fields of science, technology and culture (von Bertalanffy, 1968; Richmond, 1991; Fritjof Capra, 1996), especially dynamic systems, understood as entities that appear to be unitary to the observer but in fact are make up of a variety of interacting variables that are causally interconnected through "loops" of various size and often nested (Mella, Gazzola, 2018).

Systems thinking plays a dominant role in a wide range of fields from industrial enterprise and armaments to esoteric topics of pure science (von Bertalanffy, 1968, p. 3).

According to Senge's interpretation, Systems Thinking represents the most rational way of thinking in every dynamic environment, in which systems are represented by reinforcing and balancing loops, variously linked, which connect interacting variables.

Systems thinking is a discipline for seeing wholes. It is a framework for seeing interrelationships rather than things, for seeing patterns of change rather than static "snapshots" (Senge,1990, p. 68). 
Systems Thinking [is] a way of thinking about, and a language for describing and understanding, the forces and interrelationships that shape the behaviour of Systems. This discipline helps us see how to change systems more effectively, and to act more in tune with the larger processes of the natural and economic world (Senge et al., 1994, p. 6).

Nevertheless, Systems Thinking not only represents an efficient tool for easily building coherent and sensible models of the dynamic and ever-changing world and environment in which people, organizations and society operate, but also a mental attitude, an approach (Meadows, 2008; Wright and Meadows, 2012; Hitchins, 2017), a logic and a language (Anderson and Johnson, 1997; Richmond, 2000) that obliges us to follow several basic rules. In his book "Systems Thinking, Intelligence in Action" (2012), Piero Mella, formalizes Senge's Systems Thinking view anddelineates a simple framework which defines a set of necessary and, perhaps, sufficient rules for the construction of the systems models.

First rule: if he wants to understand the world, the observermust be able to "see the trees and the forest"; he must develop the capacity to "zoom" from the whole to the parts, from systems to components, and vice-versa, by always considering objects as elements of a vaster system. This rule indicates the art of placing oneself at the proper distance to grasp both persons and the crowd, both the dynamics of the individual and that of the crowd; both the trees and the forest, the dynamics of the trees and that of the forest; both the houses and the village, the cells and the tissues, the organs and the organism, and so on.

Second rule: the observer must not limit his observation to that which appears constant but "search for what varies"; the variables are what interest the systems thinker. However, the observer must not limit himself to explicitly stating the variables he considers useful but be able to measure the "variations" they undergo over time. The systems of Systems Thinking are systems of variables, not systems of objects; they are dynamic, not ordinal systems.

Third rule: if he truly wishes to understand reality and change, the systems thinker must make an effort "to understand the causes of the variations in the variables he observes"; he must form chains of causal relationships among the connected variables. However, this is not sufficient: we also need a Fourth rule:

Fourth rule: it is not enough to search for the causes of the variations we observe; the observer must also "link together the variables in order to specify the loops among all the variations". In other words, the systems thinkermust move from the causal chains to the systemic interconnections and from the linear variations to the systemic interactions among the variables of interest. Independently of the type of variables observed, the systems of Systems Thinking are always formed by variables interconnected by reinforcing and balancing loops.

Fifth rule: when he observes the world, the systems thinkermust "always specify the boundaries of the system hewishes to investigate".He cannot consider a crowd, forest or village that is endless. The systems of Systems Thinking must have a boundary.

As a consequence of adopting the framework presented here, it follows that:

Systems Thinking defines "system" as a unitary set of interacting variables, interconnected by loops - capable of producing emerging macro-dynamics that do not coincide with any of the micro-dynamics of the individual variables or their partial subsystems - whose logical structure it investigates and represents (Mella, 2012, p. 21).

Due to its intrinsic logic, which observes a world of variables and of variations, Systems Thinking considers dynamic systems of any kind in any field (Forrrester, 1961), building models of a complex world of incessant movement in continual transformation and evolution.

Senge sorts two types of complexity from this - detail complexity and dynamic complexity. Detail complexity arises where there are many variables, which are difficult, if not impossible, to hold in the mind at once and appreciate as a whole. Dynamic complexity arises where effects over time of interrelatedness are subtle and the results of actions are not obvious; or where short term and long term effects are significantly different [...]. (Flood, 1999, p. 13).

Senge's and Mella's Systems Thinking frameworks provide not only the concepts but also the techniques for constructing models of dynamic systems: that is, the Causal Loop Diagrams (CLD). A CLD consists of a system of loops in which all variables are linked by arrows, without there being an initial and final variable. All the variables are connected. Senge's method immediately spread(Anderson and Johnson, 1997; Checkland, 1999; Haines, 2005; Richmond, 1991, 1993; Sterman, 1994, 2000; Swanson, 2002).

Expressed quantitatively, systems thinking adopts the simulation procedures of system dynamics, a discipline and technique that unquestionably goes back to Jay Forrester and his fundamental book Industrial Dynamics (Forrester 1961) (see also: Forrester, 1999). In recent works Forrester defines systems dynamics as follows: 
System dynamics combines the theory, methods, and philosophy needed to analyze thebehavior of systems not only in management, but also in environmental change, politics,economic behavior, medicine, engineering, and other fields. System dynamics provides acommon foundation that can be applied wherever we want to understand and influence howthings change through time. The system dynamics process starts from a problem to besolved - a situation that needs to be better understood, or an undesirable behavior that is tobe corrected or avoided. The first step is to tap the wealth of information that people possessin their heads. [ . . ] System dynamics uses concepts drawn from the field of feedback controlto organize available information into computer simulation models (Forrester 1991, p. 5).

\section{The control ofdynamic systems}

Dynamic systems produce dynamics that are inconsistent (the more efforts are made to combat drug use, the more it spreads) and at times harmful to individuals (the more the roads are widened, the greater the increase is in the number of accidents) and to the community (increase in the amount of plastic waste, global warming, arms escalation, increase in violence, etc.) and that do not respond to the interests of those subject to the influence of those systems. An effort to control dynamic system variables is therefore necessary.

Simply speaking, controlling a variable means undertaking a process that leads (pushes, forces, constrains) that variable to achieve a given goal (a limit, a constraint, etc.), be this a state (regulatory control) or a succession of states, a path (tracking control) (for more: Mella, 2014). The process for controlling a dynamic system with multiple variables can act based on a feedforward or feedback control; the feedback control can be summarized as follows (symbols are taken from Mella, 2014):

- Identify and choose the variables you wish to control: $\mathrm{Y}_{\mathrm{m}}$, where $\mathrm{m}=1,2, \ldots, \mathrm{M}$;

- Position the objectives: $\mathrm{Y}_{\mathrm{m}}$;

- Identify the control variables or the "control levers", $\mathrm{X}_{\mathrm{n}}$, where $\mathrm{n}=1,2, \ldots \mathrm{N}$, and the causal/functional relationship that connects them to the variables to be controlled, $\mathrm{g}\left(\mathrm{Y}_{\mathrm{m}} / \mathrm{X}_{\mathrm{n}}\right)$, which depend on the physical structure of the elements that make up the specific dynamic systems;

- Determine, for each "instant" (appropriately defined) the "Error" (variance, deviation, gap, etc.) between the objective and the state taken on by each variable: $\left.\mathrm{E}(\mathrm{Y})=\mathrm{Y}^{*}-\mathrm{Y}\right)$, for each $\mathrm{m}_{\mathrm{m}}$;

- Choose the "control levers", $\mathrm{X}_{\mathrm{n}}$, and determine the value to be assigned them, based on the dimension of $\mathrm{E}(\mathrm{Y})$, for each $\mathrm{Y}_{\mathrm{m}}$, so that, taking into account the relations $\mathrm{g}\left(\mathrm{Y}_{\mathrm{m}} / \mathrm{X}_{\mathrm{n}}\right)$, the error is gradually reduced;

- When the Error is eliminated the control has concluded, at least temporarily, so long as outside disturbances to the system do not occur that once again disrupt the level of $\mathrm{Y}_{\mathrm{m}}$.

Identifying the variables to be controlled, $\mathrm{Y}_{\mathrm{m}}$, taking into account their importance and urgency is the task of the "governance" of the dynamic system. The detection and choice of "control levers", $X_{n}$, is implemented by the "system manager". "Managing dynamic systems" means controlling the variables in them that are considered fundamental: useful or dangerous or harmful.

The term "control system manager" is in line with its use in Management Science, Organization Science, and Management Control Theory in relation to organizations and to social, political, economic and environmental systems. Stafford Beer is clear in this regard when he states that: "If cybernetics is the science of control, management is the profession of control" (Beer 1966, p. 54). Even more clearly, in outlining the contribution of his book Brain of the Firm he states: "This book is entirely concerned with the contribution which cybernetics, the science of control, can make to management, the profession of control" (Beer 1979, p. 17).In fact, management control is defined by Robert Mocker as follows:

Management control can be defined as a systematic effort by business management tocompare performance to predetermined standards, plans, or objectives in order to determinewhether performance is in line with these standards and presumably in order to take anyremedial action required to see that human and other corporate resources are being used inthe most effective and efficient way possible in achieving corporate objectives (Mockler1970, p. 14).

\section{Obstacles to managing dynamic systems. A summary}

In many situations, no matter how much time and energy we dedicate to them, the construction of effective systems models is not possible or is impeded by certain conditions that make it nearly "impossible to represent" a dynamic world in all its dynamic processes and connections.

By describing brief "metaphors", in part suggested by Senge's book (1990), this study will present six of the conditions that make it "difficult, if not impossible, to perceive dynamics" and thus impede the Systems Thinker from"understanding" and "controlling" the world. 
1. Temporal slowness, or metaphor of theboiled frog. This obstacle derives from temporal slowness. A frog is immersed in a pot of cold water, under which a flame is lit that slowly heats the water. The temperature rises, but the frog - who knows nothing of pots, flames and researchers observing him - tries to resist the heat, perhaps in the hope the water will return to its ideal temperature. However, slowly, but inexorably, the heat becomes unbearable and the frog attempts to jump out of the water. Because his limbs are numb from the heat, the frog remains in the water and is boiled: he becomes a boiled frog.

2. Speed of processes, or metaphor of thenetworking effect. This obstacle is linked to the speed of processes and phenomena (usually involving accumulation and propagation based on exponential laws) that are so rapid we are not able to "recognize" their evolution until they have already produced their effects on the system. A typical case is the socalled networking effect, which operates particularly in networks of elements that propagate some information, or effect, at too high a speed to be observed, as in the case of phenomena spreading by word of mouth or pandemics.

3. Spatial distance, or the metaphor of the butterfly effect (also known as the Turing effect), the obstacle from distance in space. The term butterfly effect derives from the physicist Edward Lorenz who, in 1979, stated that if the theories of complex systems and chaos were correct, then the fluttering wings of a butterfly in Brazil would be enough to alter climate patterns, even permanently, and generate typhoons in the Caribbean.

4. Temporal distance, or metaphor of Temporal Myopia, the obstacle from distance in time. Preference for shortterm, individual or local advantages hide the collective and globaldisadvantages that will occur over the long term; for this reason, short-term, individual and local advantages are preferred to long-term and global disadvantages. In many circumstances, repetitive behavior produces short-term, individual or local advantages which encourage the continuation of the behavior even when it creates long-term collective and globaldisadvantages. The current advantages reduce the perception of the long-term disadvantages - which are thus produced with a considerable delay - which encourages even more of the same short-sighted behavior in order to gain present advantages. This, however, inexorably creates long-term problems when the disadvantages caused by the repeated behavior appear, so that the long-term disadvantages do not condition behavior but represent only its effect.

5. Observational arrow, or metaphor of themono-directional view, the obstacle from observational direction. Often people "look" in one direction only and do not "perceive" the variables taking place at their backs or in other directions, at times even choosing to ignore these. The observer adopting a mono-directional view is inside a limited system and ignores, or wants to ignore, the fact that this system is part of a larger system. Observing the small system in only one direction makes it easy to ignore the larger system that is stretching out in the other directions.

6. Complexity of structure, the difficulty linked to the structural, computational and temporal complexity of systems withmemory. This form of complexity has been well described by Heinz von Foerster (1991), the father of "second-order cybernetics", who views a system (machine) with memory - defined as non-trivial - as a complex system deriving from the interconnection of systems (machines) without memory, or trivial machines, which in Systems Thinking represent the elementary processes between two variables based on a cause-effect relation. In many cases, it is impossible to understand the extreme behavioural complexity of a system with memory because of the incredible number of behaviours [input-states-output] that a system with memory can produce.

The aim of this study is to examine in depth these six difficulties, identifying the consequences of their action in organizations and in society. Obviously, these metaphors do not describe concrete phenomena or situations that occur in laboratory experiments or real life. Precisely because they are metaphors, they must be taken as teachings to present and understand, in a simple and convincing manner, important real phenomena observable in all types of social and organizational systems

\section{Temporal Slowness, or Metaphors of the Boiled Frog and the Frozen Frog}

This obstacle derives from the temporal slowness in the evolution of certain variables that are interesting to controlbut which, due to the slowness of their change, are difficult to observe and, as a consequence, to control. No timely control of a variable is possible if the dynamics of its values are not perceived until they reach levels that can no longer be controlled. The metaphor is simple: imagine a frog immersed in a pot of cold water, under which a flame is lit that slowly heats the water. The temperature rises, but the frog - who knows nothing of pots, flames and researchers observing him - tries to resist the heat, perhaps in the hope the water will return to its ideal temperature. However, slowly but inexorably the heat becomes unbearable and the frog attempts to jump out of the water. Because his limbs are numb from the heat, the frog remains in the water and is boiled: he becomes a boiled frog. On the other hand, we can imagine that a frog in a pot of boiling water would react immediately and jump out, thereby saving his life.

Though there is nothing restraining him, the frog will sit there and boil. Why? Because the frog's internal apparatus for sensing threats to survival is geared to sudden changes in his environment, not to slow, gradual changes (Senge, 1990, p. 17). 
Meaning: Some phenomena are described by variables whose dynamics are so slow we often cannot perceive themand thus react in time when the levels of the variable reach a dangerous level. In such situations, moreover, it is not possible to control the source of the variations (the flame that heats the water); we can only react to the variable with effectors (muscles in the legs that do not respond to the stimuli), which in turn are conditioned by the values of the variables. Therefore, the reaction to the variables becomes impossible (the frog does not jump out of the boiling water and is boiled).Systems Thinking obliges us to carefully consider the small and slow variations in variables, since vital phenomena are associated with these systems- physical, biological and social - which, if not perceived when they start, could cause catastrophic consequences. We can thus interpret the metaphor of the boiled frog as an example of a failure of the control due to two factors: the heat detectors do not correctly perceive the water temperature reaching levels of maximum tolerance, and the effectors are themselves conditioned by the temperature and do not receive the impulse to react in time (Mella 2014).

Technical note.Since we are dealing with a metaphor, there is no need for empirical verification of the actual behaviour of the frog in the water being heated. Nevertheless, several researchers have conducted an experiment showing that the metaphor does not describe real situations, since a frog thrown into boiling water would die while one immersed in water that is slowly being heated would always have the strength to jump out (Wikipedia, 2018, online).

So the real story should be the exact reverse of the "fact" that's so often quoted. Put a frog in some cold water and heat it up slowly, and the frog will hop out. Drop a frog in boiling water and it will be boiled alive. Is it me, or does that sound even scarier? (Inglis-Arkell, 2014, online).

Nevertheless, several YouTube videos present experiments (without scientific scrutiny) that instead appear to confirm the behaviour of the boiled frog (Stevie 2008; PoincareDuality 2012).

The metaphor in action. The situation described by this metaphor can be observed in many real-life situations, individual, organizational and social (Teal \& Co., 2016). At the individual level, stress acts like water whose temperature is inexorably rising, and we risk becoming the boiled frog. Small doses of hard liquor, stimulants and drugs over time become ever larger doses, and when a certain limit is exceeded, such as in the case of the boiled frog, we are not able to react. At the social level, the metaphor of the boiled frog is seen in the gradual increase of deforestation, climate changes (Houghton, 1994; Maslin, 2004), plastic pollution (Hoffman, 2015; Entwistle, 2017), the spread of drugs, immigration, or the slow spread of resistant antibiotic bacteria (Martens and Demain, 2017; Powderly, 2019; IDSA, 2019). Policy makers always have difficulty in perceiving and controllingthese phenomena (Rice, 2008), which display a slow but steady increase and lead society to "be cooked" like a boiled frog. Even in organizations, the metaphor is revealed as inexorable in the form of a slow rise in competitors, the loss of market share, the slow march of products toward the declining phase of their life cycles, and the slow deterioration in organizational efficiency. The slowness of such phenomena stops managers from realizing the gravity of their dynamics, and very often organizations end up as boiled frogs.

Systems Thinking proposes an operational rule which is simple though not always easy to apply: amplify the weak signals, thereby projecting the slow variations towards a future horizon of appropriate amplitude and, above all, be aware that the "boiled frog" is always waiting in ambush and can strike without our having the time to be aware of the process that is playing out (Mella, 2012, p. 30).

Let us assume that the slow increase in variable $Y$ occurs based on the simple function $Y=(1+r)^{n}$, witha small rate of increase of $r=0.01 \%$. Although the rate of increase is modest, $Y$ will double in value in 70 years, triple in value in 111 years, quadruple in value in 140 years, and increase tenfold in 232 years. It is difficult to notice the effects of this increase in the initial decades; but after two centuries it may be impossible to control them.

Variant. The frozen frog. The situation described in the metaphor of the boiled frog applies, though with inverted dynamics, to many phenomena marked by a gradual reduction in some variable. If this reduction is slow, then we become aware of the low values reached after a long period, when it is no longer possible to remedy the effects. It is as if a frog were placed in a pot of lukewarm water and then the temperature was slowly lowered. When the frog realizes the water is becoming ice-cold, it cannot jump out because its legs are already nearly frozen. I shall call this the metaphor of the frozen frog, a situation which is also widespread and testified to by the slow extinction of species, the gradual exhaustion of resources, the disappearance of waste sites, building zones and parking areas in cities, and so on.The decline in the birth rate in Japan and in other countries can be described as a frozen frog phenomenon.

Japan suffered its biggest population decline on record this year, according to new figures that underline the country's losing battle to raise its birth rate. The data suggests the government will struggle to reach its goal of raising the birth rate - the average number of children a woman has during her lifetime - to 1.8 by April 2026. The current birth rate stands at 1.43 , well below the 2.07 required to keep the population stable. 
The National Institute of Population and Social Security Research in Tokyo estimated that more than 35\% of Japanese will be aged 65 or over by 2040 (McCurri, 2018, online)

This phenomenon is so slow that when governments realize the extent to which it is occurring, it is difficult to find Control Systems to control it.

\section{Speed of processes, or metaphor of the waterlily explosion}

This obstacle is linked to the speed of processes and phenomena (usually involving accumulation and propagation based on exponential laws) that are so rapid we are not able to "recognize" their evolution until they have already produced their effects on the system. A typical case is the so-called networking effect, which operates particularly in networks of elements that propagate some information, or effect, at too high a speed to be observed, as in the case of phenomena spreading by word of mouth or pandemics. The metaphor described below refers to water lilies, which, in an imaginary town, have a very high rate of reproduction which,to highlight the effect of the rapid growth rate, is assumed to be $100 \%$ per day. The effect would also be produced with a lower, though still high, growth rate. The metaphor describes the following situation: a farmer was passing by a lake he usually fished in when he saw a water lily, but he did not give this much thought.A couple of days later he saw four waterlilies (rate of increase assumed to be $100 \%$ per day), which pleased him since the flowers were turning the lake into a nice place not only for fishing but also for picnicking. After two weeks he saw the waterlilies had become numerous, and he thought: «In a few days I really have to remove some of those waterlilies».But it was too late by now. The waterlilies had doubled in number each night and the following day covered the entire lake, thereby not allowing the fish to survive, as a result of whichthe farmer was forced to give up his passion for fishing.

Meaning. Several variables in a dynamic system, such as the number of water lilies in the metaphor, have dynamics caused by processes of accumulation, propagation or diminution based on exponential functions with high growth rates that produce dynamics so rapid we are not able to perceive their evolution until they have already produced their effects on a system.

Technical note. Let us return to the simple function $\mathrm{Y}=(1+\mathrm{r})^{\mathrm{n}}$. With a growth rate equal to $\mathrm{r}=0.1=10 \%$, $\mathrm{Y}$ will double in 8 years. If $r=0,5=50 \%$, after 8 years the value of $Y$ will be 25 times the starting value; if $r=1=100 \%$, after 8 years $\mathrm{Y}$ will be 256 times its initial value. If we assume instead a rapid rate of decrease of $\mathrm{r}=-0.1=-10 \%$, then in 7 years $\mathrm{Y}$ will be halved; if $\mathrm{r}=-0.5=-50 \%$, in 7 years $\mathrm{Y}$ will decline to seven-thousandths of the initial value. A high rate of growth or decline leads to a very rapid dynamic process for $\mathrm{Y}$ that is difficult to perceive and even more so to control.

The metaphor in action. A typical case where it is difficult if not impossible to see the dynamics of a system is the socalled networking effect, which operates especially in networks of elements that propagate some information or effect.An element initiates the propagation of two or more related elements, and this process is disseminated to other elements in the network so that - just as in nuclear fission - a cumulative dynamics occurs which is so rapid as not to permit observation while it is being produced. We become aware of the dynamicsonly when "we see" the global effect, which usually has some undesirable aspects, as in the case of phenomena spreading by word of mouth or pandemics. Even the rapid reproduction of many animals and invasive plants appears at times to be a sudden "explosion". An example of this is the explosion in the increase of rabbits in Australia.We know that rabbits represent a big ecological problem in Australia. Rabbits were imported to Australia at the end of the $18^{\text {th }}$ century (probably in 1788) to provide a supply of meat to the inhabitants. The imported rabbits, which were particularly strong and fast, quickly proliferated exponentially, setting off a typical population explosion phenomenon for rabbits. No attempt at control (hunting, the destruction of warrens, the infection of rabbits with the Myxoma virus, etc.) was successful.

Mella (2014), has constructeda quantitative simulation model of the rabbit explosion phenomenon based onthese assumptions:

a. a period of 100 years; an initial population of $\mathrm{X}_{0}=24$ pairs; each of the newly imported specimenspairs with one already present;

b. a rate of population increase (fecundity rate-mortality rate) at the start of the process of $\mathrm{g}_{0}=6 \%$; it is assumed that, partly as a result of the attempts by authorities to limit the phenomenon, the rate " $\mathrm{g}$ " diminishes with the increase in population: $\mathrm{g}_{50}=3.5 \% ; \mathrm{g}_{59}=3 \% ; \mathrm{g}_{75}=2.5 \% ; \mathrm{g}_{88}=2 \%$;

e. it is assumed that for each generation only a percentage $h=75 \%$ of the new individuals contributes to increasing the population; the remaining ones are prey for the predators; it is also assumed there are 6 pairings per year; this datum is inserted into the model by simply setting $r=0.167$. 
The model shows that after 100 years - the equivalent of 600 generations $(r=0.167$, didactic assumption $)$ - the rabbit population reaches about $X_{100}=2.30$ billion pairs of rabbits. Since Australia has a surface area of 7,617,930 $\mathrm{km}^{2}$, the model shows that after 100 iterations there will be an average population of 300 pairs of rabbits per square kilometre. If we assume that the authorities succeed in introducing new predators for rabbits, so that the number of newborns not yet at the reproductive age falls to $\mathrm{h}=50 \%$, then the population would reach a density of only one pair per square kilometer.

Resistance and resilience. Systems Thinking observes that the only defenses against the rapidity of the dynamics of some variables - a river rapidly becomes impetuous and overflows, causing disasters and serious damage(Majchrzak et al., 2007)- are a careful monitoring of the causes of the variation - rain intensity, high water levels downstream, etc. and an increase in the resistance and resilienceand a reduction in the vulnerability(Ellison et al., 1997;Allen, 1997) of the structures that would suffer the effects of rapid increases in the variables, by raising the banks of rivers, digging channels for the removal of water, etc. (Kaushal et al. 2007).

A common point to the above senses of the notion of resilience is the ability to successfully accommodate unforeseen environmental perturbations or disturbances (Laprie, 2008).

At the same time, in the arena of resilience were evidenced conflicts among different cultures, methodologies and approaches (Lucini 2014). This produces catastrophic effects comparable to the ones of material disasters, not only as it concerns the evaluation of risk but for its practical implications (Garven, and Lamm-Tennant 2003). In any case it remains the problem of evaluating approaches to resilience and of adjusting conflicting measures of performance (Bianchi, 2019).

Joint action of the metaphors of the boiled frog and the water lily explosion. For at least 100,000 years, the human population has undergone a very slow increase which no one has perceived. This increase became evident to man only when itreached significant levels, no matter how low the expansion rate was: from around 300 million people 2,000 years ago,population has risen to its present level of 7.5 billion, which represents a very low average rate: CAGR = $0.0161 \%$.If we consider that the population estimated in 1800 was around 980 million and that presently it stands at 7.5 billion, then over the last two hundred years the average rate has risen to CAGR $=0.0942 \%$. The growth in population has become of concern because the growth rate has increased, thereby heightening the effect of exponential growth. This teaches us that the situations described in the two metaphors (boiled frog and water lily explosion) often act jointly. A slow growth that is difficult to identify becomes a problematic explosive growth that needs to be checked. It is also true that in some areas of the world the population is in decline, and it is difficult to recognize this trend and take steps to halt it, thus exposing those areas to the same end as that of the frozen frog. And what about the growth in the use of robots? There are around 17 million industrial robots in use in factories around the world that are characterized by repetitive and dangerous work environments.

"In terms of units, it is estimated that the worldwide stock of operational industrial robots will increase from about 1,020,700 units at the end of 2009 to 1,119,800 at the end of 2013" (ASME, online).However, robots today create concern since they increase the productivity of processes and make it less profitable to employ human labor. The decline in employment still appears slow, but without the necessary measures the metaphor of the frozen frog is waiting just around the corner.

Kurzweil's Law of Accelerating Returns. An important example of how the mechanisms underlying the two metaphors can act jointly is provided by Ray Kurzweil's theory $(2001,2005)$ in his Law of Accelerating Returns (Mella, 2018a). To understand this theory we start by observing that the change in the environmental variables which, until yesterday, were studied in terms of velocity (boiled frog) have recently been employed to examineacceleration (water lily explosion), which affects all aspects of our world: technology, public life, political movements and wars, economic dynamics (Evans, 1991), as well as social aspects (Rosa, 2003).As recognized by Ray Kurzweil, during the age of the Pharaohs or, 2,000 years later, the Romans, technological progress, military conquests, power dynamics, changes in the borders between states, and other macro phenomena were interconnected but followed an understandable dynamics in terms of a slow linear evolution based on constant rates of change. For some years now, such linear dynamics have given way to the gradual "reinforcement" of the speed of change of all phenomena; that is, anacceleration of change has caused anincrease in the rates of change of the different variables in the system.

An analysis of the history of technology shows that technological change is exponential, contrary to the common-sense "intuitive linear" view. So we won't experience 100 years of progress in the 21 st century — it will be more like 20,000 years of progress (at today's rate) (Kurzweil, 2001). 
Technical note. The acceleration in the variations pointed out by Kurzweil occur when two (or more) variables $\mathrm{X}_{\mathrm{t}}$ and $\mathrm{Y}_{\mathrm{t}}$, which form a loop, not only produce the reciprocal variations but also lead to a gradual increase in the variation rates $-\mathrm{f}(\mathrm{Y})$ and $\mathrm{g}(\mathrm{X})$ - of the variables (or at least in one of them), as shown in the model in Figure 1, where the variable $Y$ also impacts the rate $f(Y)$, based on the function $k=G(Y)$, and the variable $X$ impacts the function $g(X)$, based on the function $h=F(Y)$, thereby accelerating the variations in the interacting variables.

Figure 1. Loop showing the action of accelerating returns

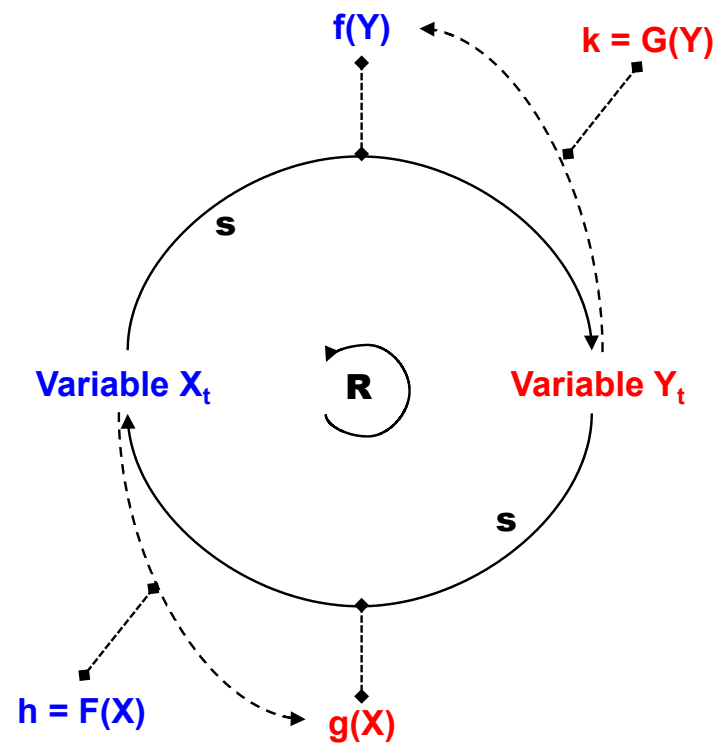

(Source: Mella, 2018a, p. 193)

In the economic and technical world, the modus operandi of the model in Figure 1 is not an exception but the rule (Castera, 2016); Figure 2 shows an example of how the law of accelerating returns impacts the growthin electronics and informatics.

The Law of Accelerating Returns tells us that we will experience a century's worth of progress in just 25 years. This may seem counterintuitive, but it is not; rather, it takes into account the fact that the rate of technological change increases all the time. The rate at which humanity advances this year will increase by next year, and so will the rate at which technology advances. Technology will evolve to replace what humans spend most of their time doing. Grunt work that humans would cast aside if given the chance will instead be taken on by artificial intelligence. The Law of Accelerating Returns will escort humanity upwards into infinity from our contemporary linear perspective (Tithof, 2016).

Second technical note. What causes a slow dynamic process to be transformed into a fast, and at times explosive, one? Systems Thinking offers a very simple formal explanation. The slow dynamics is almost always due to a simple law of linear accumulation of the type $\mathrm{Y}=(1+\mathrm{rn}), \mathrm{r}>0$; if " $\mathrm{r}$ " is negative, there is a decrease. When $\mathrm{Y}$ increases (decreases) beyond a certain limit, the dynamics become non-linear since one or more reinforcement loops between $\mathrm{Y}$ and other variables that interconnect and interact with it come into play. The increase in Y leads, for example, to an increase in a variable $\mathrm{Z}$, which interacts with $\mathrm{Y}$ in a reinforcing loop, which leads to a further increase in $\mathrm{Y}$, which once again increases Z, and so on, for several recursions typical of the systems in Systems Thinking. An example: after a period of slow growth, the increase in the "greenhouse gases" as a result of man's production and consumption activity become significant and preoccupying. By trapping the heat from the sun's rays, the greenhouse gases become a determining factor in "global warming", which leads to the gradual warming of the soil, causing the growth of trees that retain heat, and of the seas, causing an increase in dark algae that produces the same effect. Moreover, global warming causes the melting of glaciers at the North and South Poles, thereby reducing the "albedo effect" and leading to a new increase in the Earth's temperature, and in the tundra, causing the escape of methane bubbles (which before were trapped in the ice) that further increase the greenhouse gases. By the time we become aware of global warming it is too late to take remedial action due to the action of these and other reinforcing loops that are difficult to control. The dynamics of a variable are never isolated, since every variable is contained in dynamic systems of interacting variables. 
Figure 2. The action of the law of accelerating return on the growth in electronics and informatics

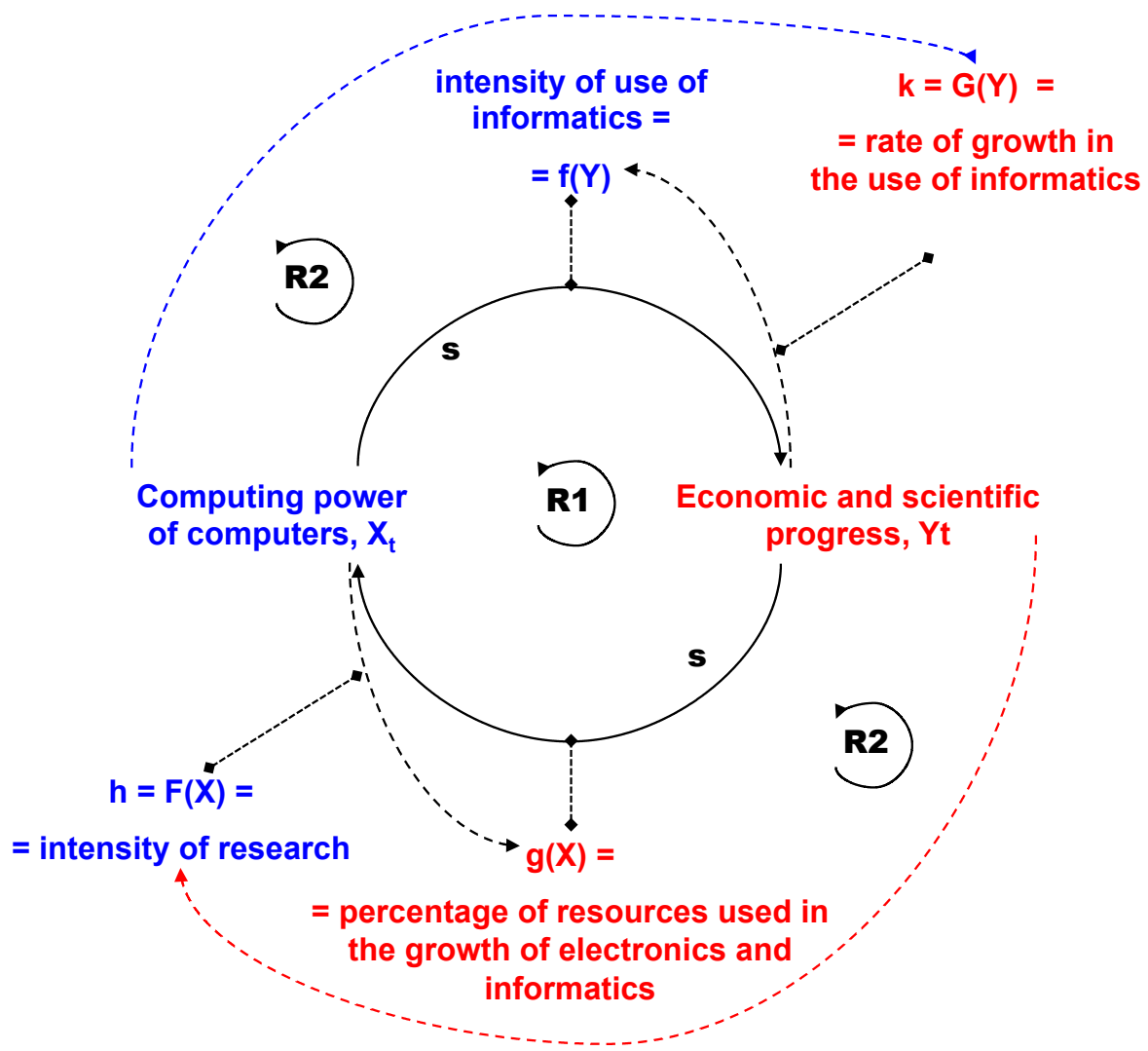

(Source: our elaboration of the model in Kurzweil, 2001, on line)

\section{Spatial distance, or metaphor of thebutterfly effect (also known as the Turing Effect)}

This metaphor highlights the obstacle resulting fromthe distance in space of the effect of a certain cause.The term butterfly effect derives from the physicist Edward Lorenz who, in 1972, at a meeting of the American Association for the Advancement of Science, gave a speech entitled "Does the flap of a butterfly's wings in Brazil set off a tornado in Texas?", provocatively stating that if the theories of complex systems and chaos were correct, then the fluttering wings of a butterfly in Brazil would be enough to alter climate patterns, even permanently, and generate typhoons in the Caribbean, or suffice to alter climate patterns, even permanently.However, Lorenz also stated that: "If the flap of a butterfly's wings can be instrumental in generating a tornado, it can equally well be instrumental in preventing a tornado" (Lorenz, 1972, p. 1)..

Alan Turing expressed a similar idea in saying that shifting a single electron at a given time by a billionth of a centimetre could, thanks to a very long cause and effect chain, give rise to very diverse events, such as the death of a man a year later due to an avalanche or his being saved (Turing, 1950). For this reason, the butterfly effect is also known as the Turing Effect (Wikipedia, 2019).The effects of a "very small cause" that produces "considerable effects" had already been pointed out by Jules Henri Poincaré:

A very small cause which escapes our notice determines a considerable effect that we cannot fail to see, and then we say the effect is due to chance [...] But it is not always so; it mayhappen that small differences in the initial conditions produce very great ones in the final phenomena. A small error in the former will produce an enormous error in the latter. Prediction becomes impossible, and we have the fortuitous phenomenon (Poincaré, 1908, p. 3).

Meaning.There are systems - composed of a very high number of variables that interact, being linked by nested loops contained in other loops - so complex that even a slight variation in the value of one of the variables is enough to produce cumulative effects that spread throughout the entire system, thereby altering other variables distant in time and space (Andrews, 2011). The difficulty is not in "observing" the final effects (tornadoes and typhoons) but in perceiving the variations which are minute and distant in time (we should not forget that this is only a metaphor and that it is hard to imagine attributing tornadoes to the fluttering wings of a butterfly). 
Systems Thinking suggests this operational rule: do not limit yourself to seeing the "forest" - the entire system - but instead zoom in toward the "trees", their "large branches" and "small branches" (their constituent parts) while considering increasingly minute variables that can give rise to the initial variations, with effects that are difficult to foresee and which are produced by the interconnections at increasingly vaster levels.

Technical note. System Thinking, in accepting the holistic view of the world, is no longer based only on cause-effect relations but above all on feedback, on the reciprocal influence between cause and effect phenomena.Therefore, we must always examinethe action of the loops of interconnections in recursive phenomena. While Lorenz and Turing appear to observe the dynamics in one direction, Systems Thinking must go further and exploit the power of reinforcing loops(Mella, 2012).

The metaphor in action. The effects described by this metaphor are common though difficult to grasp in the real world, since we try to identify the "nearby causes" behind certain macro events even though these are probably the result of small causes very distant in space and (usually) time.

Even if it may sound improbable, the butterfly effect is always lurking, and it manifests itself in many forms: a truck travelling slowly along a stretch of highway can cause a slowing of traffic that blocks the flow of connected stretches of highway, thereby causing a kilometers-long queue even on a distant stretch of highway. A local student protest that blocks traffic on a London street can cause a traffic jam involving the entire city. Resentment among leaders of minor parties can lead to a political feud that brings down the government. The wrong word whispered at a party at a friend's house can ruin a marriage. A small border incident in some part of the world can produce an escalation that leads to a war of devastating proportions. A modest variation in the number of animals in a given population can produce devastating effects and lead to the extinction of other populations linked to it (Mella, 2012, p. 31).

\section{Temporal distance, or the metaphor of Temporal Myopia}

This metaphor - normally indicated as an archetype - highlights the obstacle caused bydistance in time.Following an individual but myopic"rationality principle", each individual-agent tends to prefer the repetitive behavior that brings short-term, individual and local advantages, ignoring the long-term, collective and global disadvantages that such behavior can produce (Figure 3). This, however, inexorably creates long-term problems when the disadvantages caused by the repeated behavior appear, so that the long-term disadvantages do not condition behavior but represent only its effect (Mella, 2012; Mella and Pellicelli, 2018).

Figure 3."Short-Term, Local and Individual Myopia Metaphor"

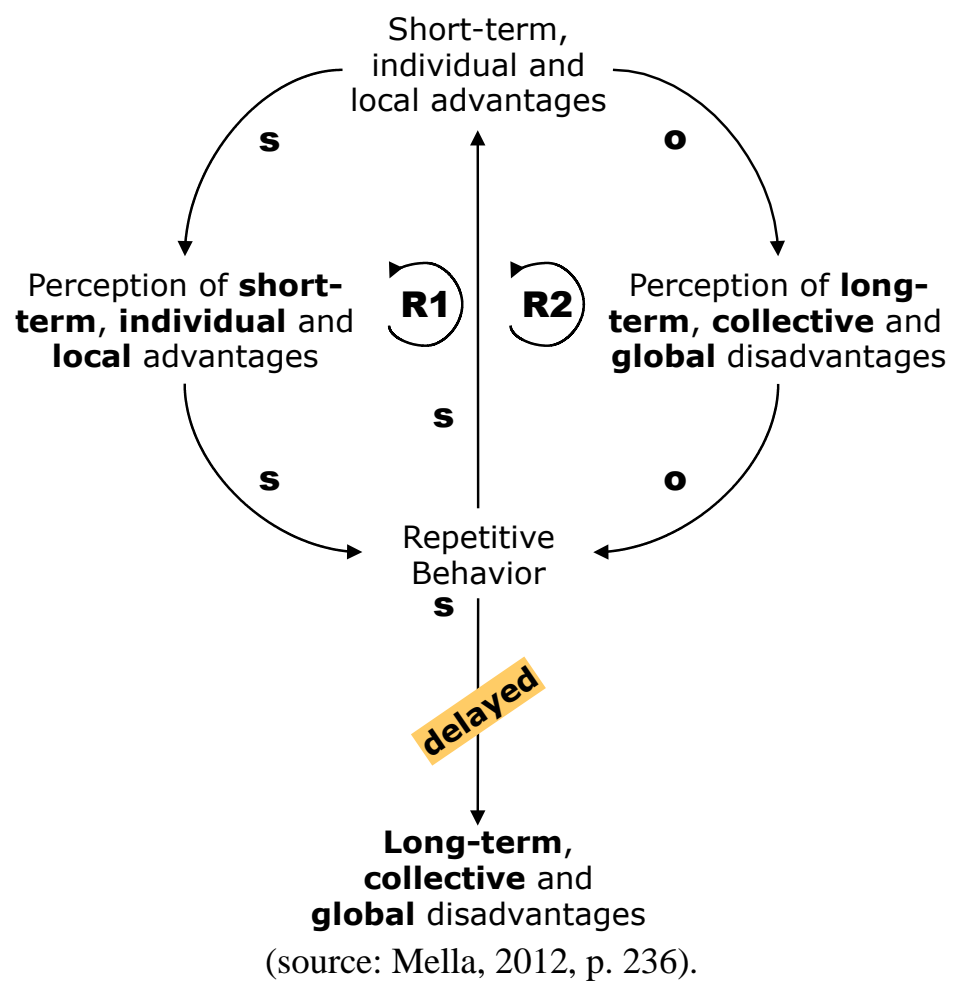


Meaning. The effect of myopic rationality is twofold: on the one hand, it focuses and overestimates the short-term advantages from repetitive actions, which provide incentives to continuing such advantageous behavior; on the other hand, the current, immediately-perceived advantages lead decision-makers to ignore, or underestimate, the long-term disadvantages - which are thus produced with a considerable delay - thereby bringing out more clearly the short-term advantages.

The metaphor in action. The myopic behavior described by this metaphor represents the engine behind many individual and group dynamics. The typical behavior of the smoker who prefers the pleasure of smoking one cigarette after another, day after day, year after year, considering as very remote the risk of getting a serious pathology from smoking, is well described by this metaphor. Replace "cigarette" by alcohol, stimulants, drugs, etc., and we see the metaphor in action. The obligation of cigarette manufacturers to write on the pack that smoking (alcohol, stimulants, etc.) is harmful to health serves no purpose. The consumer knows the short-term pleasure smoking brings him and thus continues to smoke, ignoring the risk. We also all know how convenient plastic bags are at the supermarket or the use of throwaway plastic plates and cutlery, and so we continue to use them, underestimating the pollution risk to our planet, even when we discover that fish are also harmed by swallowing micro-plastics. Global warming andthe disappearance of waste disposal sites are social examples of the consequences of this metaphor.Figure 4 illustrates how this archetype produces the harmful but widespread phenomenon of the tragedy of the commons (Hardin 1968, 1985; Ostrom 1990), which occurs when certain individuals, the appropriators, pursue individual, local and short-term benefits by exploiting a common resource with limited availability and not quickly renewable, known as Common-Pool Resources, or simple "commons", thus leading in the long term to the depletion of the resource and collective harm. Hardin states:

Ruin is the destination toward which all men rush, each pursuing his own best interest in a society that believes in the freedom of the commons. Freedom in a commons brings ruin to all. [. . .] As a result of discussions carried out during the past decade I now suggest a better wording of the central idea: Under conditions of overpopulation, freedom in an "unmanaged commons" brings ruin to all (Hardin 1968, p. 1244).

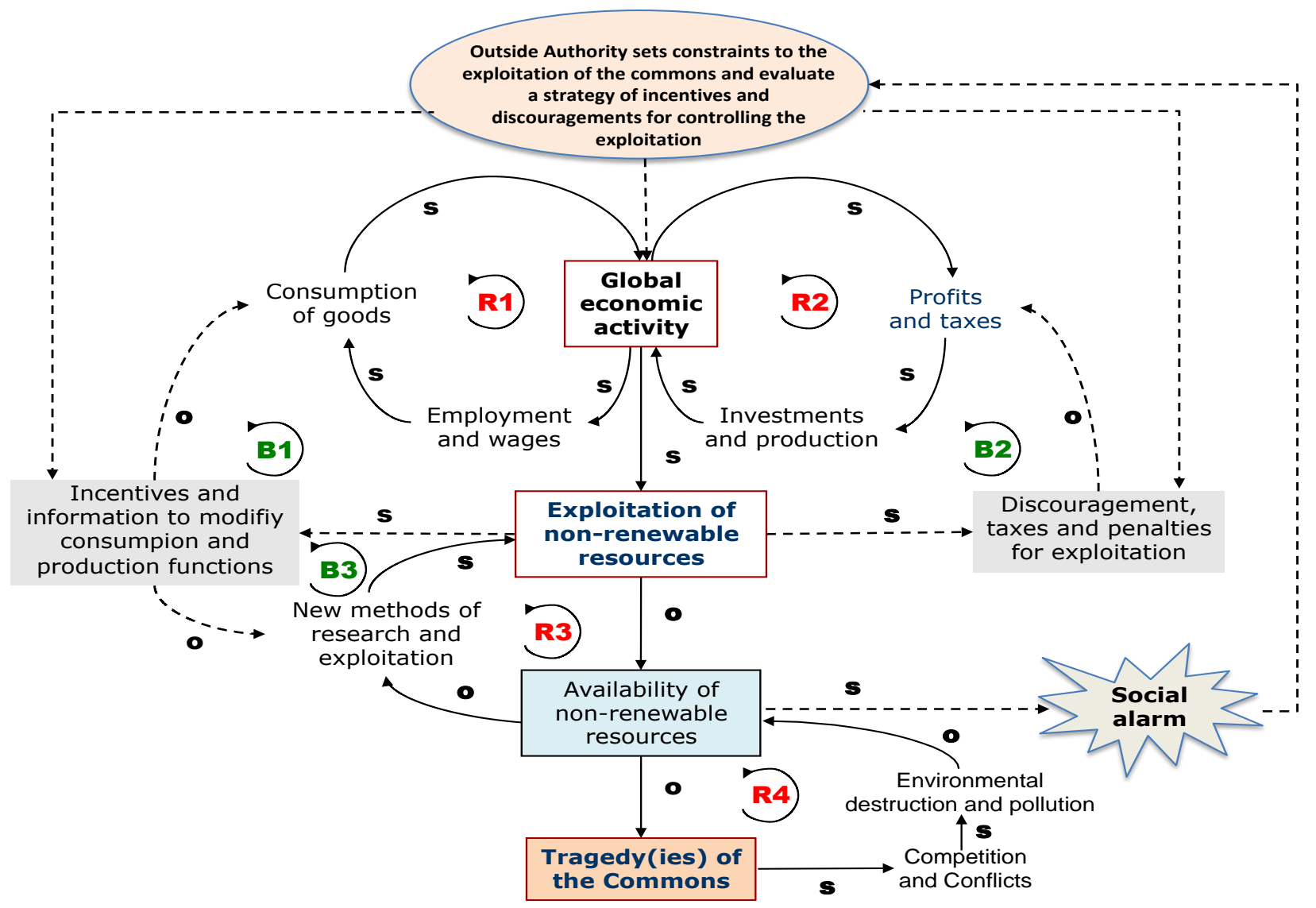

Figure 4.Hardin's Tragedies of the Commons

(source: author's elaboration) 
As illustrated in the lower part of the model in Figure 4, the scarcity of limited common resources can cause conflicts that represent a "second tragedy" included in the tragedy of the commons. The clearest evidence of this are the numerous wars fought over gold, other precious metals, water and territories, which are among the most limited and scarce vital goods on earth.

Technical note. The connection with other metaphors. The Temporal Myopia metaphor can be easily linked to that of the boiled frog. Short-term repeated behavior leads to the slow increase in the long-term disadvantages, until the point is reached when the agents are "boiled" because they are unable to stop or control the harmful effects they themselves have produced.

Second Technical note. How to combat myopic behavior. As shown in Figure 5, to reduce or cancel the harmful effects from repeated individual behavior, Systems Thinking proposes opposing the reinforcement effects of loops [R1] and [R2] with three important actions, or levers (Mella, 2012; Mella, Pellicelli, 2018).

Figure 5. Three actions to combat "myopia"

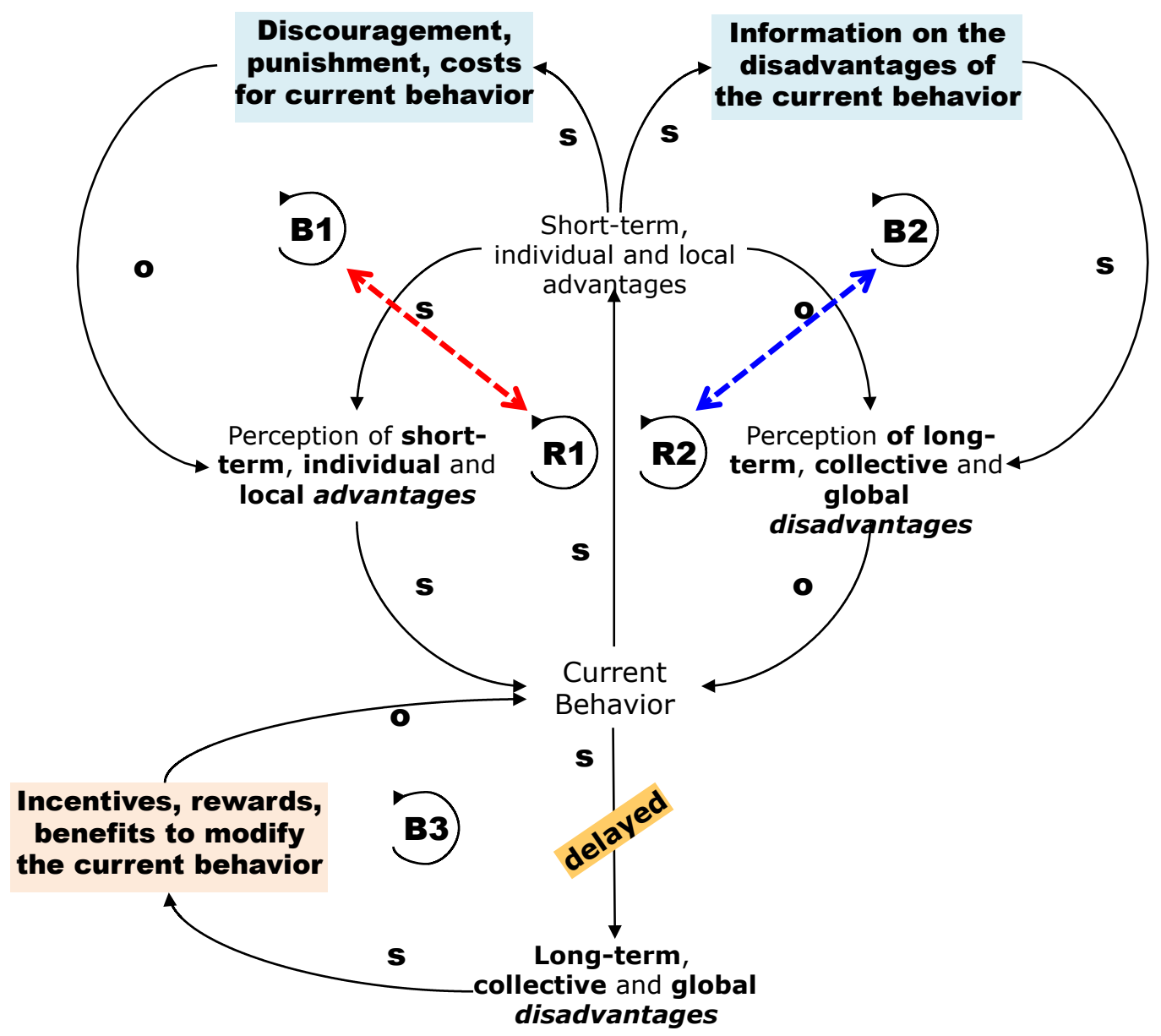

(source: author's elaboration)

FIRST LEVER - Weaken or cancel loop [R1]. Since individual advantages immediately make clear the benefits of the repeated action, an appropriate system of disincentives - even in the form of penalties and specific costs and taxes which are proportionate in some degree to the amount of the advantages, would reduce the perception of the convenience in repeating the current behavior, thereby reducing the number of repetitions.

SECOND LEVER - Weaken loop [R2] through incisive, thorough and persistent information and education about the damage caused by/to the agents by their repeated behavior. The persuasive capacity of the information must be proportionate to the quantity of short-term, individual and local advantages. The more significant these are, the more insistent, repeated, uniform, credible, convincing and thorough the information must be, even in populations in large areas. 
THIRD LEVER - Intervene directly on the agents' repeated behavior through incentives, even in the form of social and economic benefits, rewards, tax relief, etc., that convince them to reduce the intensity and frequency of their actions and to use processes, technologies and methods that reduce the long-term, collective and global disadvantages.

\section{Observational arrow, or metaphor of the mono-directional view}

This metaphor can be expressed as follows:

The mayor of a pleasant mountain town was desperate. Every afternoon at about the same time the road from the valley to the mountain top suddenly filled with cars, forming a slow-moving line several kilometres long which just as suddenly disappeared. He put the town experts to work to monitor the traffic flow, andthey found to their surprise that every afternoon a car passed along the road at the same time going at normal speed with an elderly couple aboard. When the car got close to the top of the mountain it slowed down and went very slowly for a couple of kilometres: by creating a "bottleneck" for the drivers behind them, the elderly couple caused the traffic jam. Traffic flowed smoothly again when they resumed their normal speed. When called in by the mayor, the elderly driver said: «I know nothing of the traffic you're referring to. I never saw any. We've been taking this road for weeks and when we are at the top we slow down because we never tire of the view from the top, which is always covered in snow. Believe me: we've never seen any traffic» (Mella, 2012, p. 32).

Meaning. This metaphor illustrates the obstacle caused when there is onlyone observational direction.Often people "look" in one direction only and do not "perceive" the variables taking place at their backs or in other directions, at times even choosing to ignore these; those who only "look" ahead donot "see" behind themselves. The observer adopting a mono-directional view is inside a limited system and ignores, or wants to ignore, the fact that this system is part of a larger system. Observing the smaller system in only one direction makes it easy to ignore the larger system that is spreading out in the other directions.A typical example of "mono-directional view" is described by Peter Senge as "I am my position", which he considered as a learning disability:

Most see themselves within a "system" over which they have little or no influence. They "do their job," put in their time, and try to cope with the forces outside of their control. Consequently, they tend to see their responsibilities as limited to the boundaries of their position (Senge, 1990, p. 17).

The meaning of "I am my position" is clear: those suffering from this learning disability, the mono-directional view, are not able to perceive themselves as part of an organizational or social structure in which their positions must not limit their interactions with the other elements in the system.

When people in organizations focus only on their position, they have little sense of responsibility for the results produced when all positions interact. Moreover, when results are disappointing, it can be very difficult to know why. All you can do is assume that "someone screwed up" (Senge, 1990, p. 18).

The metaphor in action. It is customary to deforest tree-filled areas - woods and forests - to build homes, factories and roads, or to acquire cultivable land for survival (Puplett, 1919; Harder, 1958; Fuwape, 2001).

Deforestation or clearance occurs due to several reasons, to get an overview we could include the need of money, both in terms of profitability as well as providing for one's family in most scenarios, along with lack of or no forest laws, need for land space for housing etc among a long list of other uses. Mainly blamed on agricultural or pastoral use, farmers fell trees for increasing space for cultivation and/or as fodder land for grazing and surviving live stock. The whole concept of 'slash and burn' agriculture, is used to indicate this same process where farmers employ the above chain of actions for their purposes (CEF, 2019, online).

Farming, grazing of livestock, mining, and drilling combined account for more than half of all deforestation. Forestry practices, wildfires and, in small part, urbanization account for the rest" (Nunez, 2019, online).

Those who do so are only looking at their specific short-term interests (looking ahead) and do not (or do not want to) see the damage deforestation causes to the ecosystem (looking back). The same is true for poachers of elephants and rhinoceroses for their ivory and tusks, whale hunters or coral fishermen, etc., who, for immediate gain, risk extinguishing entire populations of animals or even entire species. An example of a mono-directional view are governments that build dams on large rivers to obtain energy and water for cultivation upstream, without considering the damage produced downstream. The same holds for industrial policies that aim at a continual increase in productivity through increasingly intensive machinery - for example, automatically controlled machinery and robots that replace human labor (Mella, 2018b, p. 308). "In terms of units, it is estimated that the worldwide stock of operational industrial robots will increase from about 1,020,700 units at the end of 2009 to 1,119,800 at the end of 2013" (ASME, online). 
The entire world robot population reached 8.6 million at the end of 2010 (Guizzo, 2010), and in 2016 the global robot population was 17 million (ASME, online). Such policies appear rational from the viewpoint of the individual company, but when we consider the entire network of companies, policies that substitute men with machines represent a typical case of a mono-directional view, since they do not take into account the reduction in employment the use of more machinery would provoke.

Systems Thinking suggests a simple operational rule: when you are producing variations in a variable, always remember that this is connected upstream with other variables that will in turn be modified. Ignoring the interactions upstream is a common error the systems thinker must avoid. To do so, he must tryto zoom in by placing himselfoutside the observed partial system to look for the loops with the other subsystems, which helps to overcome the obstacle to correct systemic observation. What systems thinking can never prevent is the desire to consciously turn one's gaze elsewhere in order not "to see".

The connection with other metaphors. It is immediately clear that this metaphor can be seen as a special case of the more general Temporal Myopia metaphor.

\section{Complexity of the structure of systems with memory}

Complexity of structure is the difficulty linked to structural, computational and temporal complexity of systems withmemory, or non-trivial machines (von Foerster, 1984, P. 10). The key feature of a non-trivial machine is that its "input-output relationship is not invariant, but is determined by the machine's previous output. In other words, its previous steps determine its present reactions" (von Foerster, 2003, p. 143).

Today everything appears connected due to the existence of multiple relations among variables. The variables in an environment that varies at a low and constant speed are almost always linked by cause-effect relations, thereby forming causal chains that are simple to observe and control. In an accelerated world we see evidence of the shifting from open causal chains to systemic interaction, in which the dynamics of phenomena are no longer definitively oriented but instead present circular dynamics that can be represented as very large causal loops diagrams (for ex: Yang -Li and Chuanhong - $\mathrm{Xu}, 2013$.) The variables that compose a non trivial dynamic system and the environment not only change in an accelerated manner, but their variations become interdependent, forming a unitary dynamic system (Mella, 2012, ch. 2), in the sense that the dynamics of a variable interferes with that of the others through multiple reinforcing or balancing loops, thereby forming vast systems which are complex and difficult to describe, analyze and simulate (Senge, 2006, Ch. 5).

Meaning. The existence of complex dynamic systems represents perhaps the main reason for the extreme difficulty in controlling the dynamics of individual variables, since the dynamics of any single variable depends on the loop structure it is a part of, either as a cause or an effect. The observer is forced to adopt a holistic and holonic perspective (Koestler, 1967; Wilber, 2000; Mella, 2009), which increasingly blurs the distinction between variable and system and between system and environment. Every system belongs to a super system, and the reality observed appears as a super system of connected and nested super systems that becomes a "global", and thus "closed", system which must be studied as a whole and whose behavior becomes counter-intuitive due to the loops and delays.

Technical note. Today, everything appears connected due to the existence of multiple relations among variables. In a complex world we see evidence of the shifting from open causal chains to systemic interaction, and the variables present circular dynamics that can be represented as loops, thereby forming vast systems which are complex and difficult to describe, analyse and simulate (Senge, 2006, Ch. 5). In an interconnected world, we must abandon linear thinking (chains of cause and effect) and accustom ourselves to systemic thinking, observing reality as a system of loops that bind all variable phenomena (Roberts, 1978; Richardson, 1991; Senge, 2006; Mella, 2012).

Complexity of structure in action. According to Systems Thinking approach,managers of control systems must keep in mind that the interactions betweenstructure and components (Section 5) in dynamic systems present three very relevant difficulties:

(1) It is useless to try to modify the values of a variable if first we do not understandthe systemic structure of which it is a part, as the balancing loops will restore itsvalue and the reinforcing loops will increase it.

(2) Even if we are not aware of it, in every systemic context the reinforcing loops arealways linked to some balancing loop, and vice-versa.

(3) In observing a dynamic world, the "ceteris paribus" assumption is never valid. 


\section{Conclusions}

Will men and collectivities survive deforestation, species extinction, climate changes, global warming, contagions, pandemics, overpopulation, pollution, escalations of actions and reactions, feuds and wars? Will they be able to activate the loops to produce the improvement in productivity, quality and civic sense necessary to guarantee progress in living conditions? Will our leaders, policy makers and managers be able to construct Control Systems that are effective in bringing the values of the system variables to acceptable levels? Systems Thinking offers hope, since it represents a way of thinking that favors the construction of models that facilitate the understanding, knowledge, and therefore the intelligence of the agents. Nevertheless, at times Systems Thinking, despite its cognitive power, is difficult to apply to processes or systems whose dynamics depend on those variables that are, by nature, difficult to perceive, model or control.

Systems Thinking offers hope, since it represents a way of thinking that favours the construction of models that helpmanagers to understand and control these phenomena. Nevertheless, at times Systems Thinking, despite its cognitive power, is difficult to apply to processes or systems whose dynamics depend on those of several variables thatare, by nature, difficult to perceive, model or control.

This paper has considered six such difficulties, which have been presented in the form of metaphors. Some processes are so slow that we are not able to perceive their dynamics; by the time we become aware of their effects, it is too late to control them, and we end up like a boiled frog (first metaphor).At other times, processes are so fast, explosive and exponential that by the time we become aware of them there is no time to undertake any control, and we end up like the pond suffocated by the waterlilies (second metaphor).Some processes derive from the concatenation of many loops, which are contained in other loops of varying size, so that their macroscopic effects are the result of the action of micro effects produced by miniscule loops, often distant in space from the observation point. When, in a far-off land, a butterfly flutters its wings, it can unleash a chain of vortices which, gradually gaining in strength, can set off a storm in another part of the world (third metaphor).

At times, some variables depend on the myopic behaviour of many agents who prefer to repeat behavior that produces short-term, individual and local advantages, thus ignoring the long-term, collective and global disadvantages such behavior inexorably produces (fourth metaphor).This metaphor highlights above allthe obstacle caused by distance in time. If we only look ahead and observe a restricted corner of the world, we cannot understand what is happening behind us, even at a certain distance. The mono-directional view blocks us from understanding the interactions and dynamics of events. There is nothing else to do but accustom ourselves to observing our world at 360 degrees (fifth metaphor). Our willingness to apply Systems Thinking often encounters aninsurmountable obstacle in structural and computational complexity. In a structurally complex system with internal states, and thus memory, we could insert the same inputs all our life, or all the life of the universe, and continue to observe outputs that are always different. The greatest challenge to complexity is understanding and mastering such systems (sixth metaphor). These six difficulties cannot be overcome. The only remedy is to understand their existence and sharpen even more our attention and sensitivity.

The six metaphors examined in this study represent difficulties that are not easy to overcome regarding the perception, and therefore the control, of many environmental variables and of social, economic and political systems. The only remedy is to become aware of their existence and hone even more our attention and sensitivity to them. To this end, we have also indicated for each of these difficulties some strategies that Systems Thinking proposes to deal with these problems. In particular, we want to tackle a stimulating challenge for managers: setting up "sensors" that signal in advance the start of the action of the six obstacles that make it difficult to observe and understand the dynamics of systems, so that the systems thinker will not be unprepared when he has to suffer their effects.

\section{References}

(all sites were accessed in september, 2019)

Anderson, V. and Johnson, L. (1997), Systems Thinking Basics. From Concepts to Causal Loops, Pegasus Comm., Waltham,MA.

Andrews, A. (2011). Butterfly Effect: How Your Life Matters. Thomas Nelson Inc.

ASME - The American Society of Mechanical Engineers, available at: https://www.asme.org/engineeringtopics/articles/robotics/robot-population-explosion.

Bianchi, M. (2019). Beyond the structural modelling for the analysis of organizational performances in the resilience management. Economia Aziendale Online, Special Issue, 10(1), 63-74. 
Capra, F. (1996), The Web of Life, Anchor Books, New York, NY.

Castera, L. (2016). The Law of Accelerating Returns in the Shipping Industry, available at: https://blog.octopi.co/2016/11/16/the-law-of-accelerating-returns-in-the-shipping-industry/

CEF - Conserve Energy Future (2019). Deforestation: Compromises of a Growing World, available at:https://www.conserve-energy-future.com/causes-effects-solutions-of-deforestation.php

Checkland, P. (1999). Systems Thinking. Rethinking Management Information Systems, Oxford University Press, Oxford, pp. 45-56.

Ellison, B., Fisher, D.A., Linger, R.C., Lipson, H.F., Longstaff, T. and Mead, N.R. (1997). Survivable Network Systems: An Emerging Discipline, Survivable Network Technology Team CERT® (revised May 1999).

Entwistle, A. (2017). Plastic pollution: our disposable life. FAUNA \& FLORA, available at: https://www.faunaflora.org/news/plastic-pollution-disposable-life

Evans, J.S. (1991), Making fast strategic decision in high velocity environments. Academy of Management Journal, Vol. 32, pp. 542-576.

Flood, R. L. (1999). Rethinking the fifth discipline: Learning within the unknowable. Routledge. London and NY.

Forrester, J.W. (1961), Industrial Dynamics, Pegasus Communications, Waltham, MA.

Forrester, J.W. (1991). Policies, decisions and information sources for modelling, European Journal of Operational Research, Vol. 59 No. 1, pp. 42-61.

Fuwape, J.A. (2001). The impacts of forest industries and wood utilization on the environment. Journal of Tropical Forest Resources, Vol 17 No. 2, pp. 78-90.

Garven, J.R. and Lamm-Tennant, J. (2003). The demand for reinsurance: Theory and empirical tests. Insurance and Risk Management, Vol 7 No. 3, pp.217-237.

Ghys, É. (2015). The butterfly effect. In The Proceedings of the 12th International Congress on Mathematical Education, Springer, Cham., pp. 19-39.

Guizzo, E. (2010) World Robot Population, available at:https://spectrum.ieee.org/automaton/robotics/industrialrobots/041410-world-robot-population.

Haines, S. (2005). Enterprise-Wide Change: Superior Results through Systems Thinking. San Francisco: Pfeiffer-John Wiley.

Harder, R.H (1958). Wood waste, its collection and uses. Textbook of wood Technology Volume 2. Caxton Publishers. London.

Hardin, G. (1968). The tragedy of the commons. Science, Vol. 162 No. 3859, pp. 1243-1248, available at: http://dieoff.org/page95.htm

Hardin, G. (1985). An ecolate view of the human predicament, Alternatives, Vol 7 N. 2), pp. 242-262, available at:www.garretthardinsociety.org/articles/art_ecolate_view_human_predicament.html

Hitchins, D.K. (2017), Systems approach, available at: http://systems.hitchins.net/systems/systemsapproach/

Hoffman, M. (2015). One Year after Deadly Disaster, Climbers Are Still Leaving Shit All Over Mount Everest, available at:https://news.vice.com/article/one-year-after-deadly-disaster-climbers-are-still-leaving-shit-allover-mount-everest (accessed on 26 October 2017).

Houghton, J.T. (1994). Global Warming: The Complete Briefing; Cambridge University Press: Cambridge, UK.

IDSA - Infectious Diseases Society of America (2019). Antimicrobial Resistance, available at: https://www.idsociety.org/public-health/antimicrobial-resistance/antimicrobial-resistance/

Inglis-Arkell, E. (2014). Frogs are not okay with being slowly boiled alive, metaphors be damned, available at:https://io9.gizmodo.com/frogs-are-not-okay-with-being-slowly-boiled-alive-meta-1493614589.

Kaushal, K., Dilanthi, A. and Haigh, R. (2007). Role of construction in managing disasters in developing economies. Paper presented at the Annual Bank Conference on Development Economics. Bled, Slovenia: The World Bank.

Kurzweil, R. (2001), The Law of Accelerating Returns, available at:www.kurzweilai.net/the-law-of-acceleratingreturns.

Kurzweil, R. (2005). The singularity is near: When humans transcend biology. Penguin Books.

Laprie, J.C. (2008), From dependability to resilience. In 38th IEEE/IFIP Int. Conf. On Dependable Systems and Networks, pp. G8-G9.

Lorenz, E. (1972). Predictability: Does the Flap of a Butterfly's Wings in Brazil Set Off a Tornado in Texas?. Paper delivered at the American Association for the Advancement of Science, Washington, available at:http://static.gymportalen.dk/sites/lru.dk/files/lru/132_kap6_lorenz_artikel_the_butterfly_effect.pdf.

Lucini, B. (2014). Disaster resilience from a sociological perspective: Exploring three Italian earthquakes as models for disaster resilience Planning. Springer Science \& Business. 
Majchrzak, A., Jarvenpaa, S.L., Hollingshead, A.B. (2007). Coordinating expertise among emergent groups responding to disasters. Organization science, Vol. 18 No. 1, pp. 147-161.

Martens, E., and Demain, A.L. (2017). The antibiotic resistance crisis, with a focus on the United States. The Journal of antibiotics, Vol. 70 No. 5, p. 520, available at:https://www.nature.com/articles/ja201730.

Maslin, M. (2004). Global Warming; Oxford University Press: Oxford, UK.

McCurri, J. (2018). Japan shrinking as birthrate falls to lowest level in history. The guardian, available at:https://www.theguardian.com/world/2018/dec/27/japan-shrinking-as-birthrate-falls-to-lowest-level-inhistory.

Meadows, D.H. (1982), "Whole earth models and systems", Co-Evolution Quarterly, pp. 98-108.

Mella, P. (2012), Systems Thinking. Intelligence in Action, Springer Verlag, New York and Berlin.

Mella, P. (2014), The Magic Ring, Springer: Berlin, NY, USA.

Mella, P. (2018a). The Motor Wheels of Social Complexity in Today's World. Economia Aziendale Online, Vol 9 No. 2, pp. 187-204.

Mella, P. (2018b). The law of increasing productivity, International Journal of Markets and Business Systems, Vol.3 No.4, pp.297-316.

Mella, P. (2019). Notes o Knowledge, Systems, Language and Scientific Reasoning, Economia Aziendale Online, Vol 10 No. 1, pp. 1-61.

Mella, P. and Gazzola, P. (2019). Improving managers' intelligence through Systems Thinking, Kybernetes, Vol 48 No. 1, pp. 58-78.

Mella, P. and Pellicelli M. (2018). How Myopia Archetypes Lead to Non-Sustainability. Sustainability, Vol 10 No. 1, pp. 21-44.

Nunez, C. (2019). Deforestation explained, National Geographic, available at: https://www.nationalgeographic.com/environment/global-warming/deforestation/

Ostrom, E. (1990). Governing the commons. The evolution of institutions for collective action, Cambridge University Press, Cambridge, UK.

Poincaré J.H. (1908). Chance, Science and Method, Part 1, Ch 4, available at: https://www.stat.cmu.edu/ cshalizi/462/readings/Poincare.pdf

Poincare Duality. (2012), Boiling Frog Experiment, available at: https://www.youtube.com/watch?v=bSpOzssCGmk

Powderly, W. (2019). Faces of Antimicrobial Resistance, IDSA - Infectious Diseases Society of America, available at: https://www.idsociety.org/globalassets/idsa/topics-of-interest/antimicrobial-resistance/foar-report-1-up-final1.pdf.

Puplett, D. (1919). The history of deforestation in the Highlands, available at: https://treesforlife.org.uk/forest/deforestation/

Rice, L.B. (2008). Federal funding for the st(1990 first ed.; 2006 last ed.). udy of antimicrobial resistance in nosocomial pathogens: no ESKAPE, The Journal of Infectious Diseases, Vol. 197, pp. 1079-1081.

Richardson, G.P. (1991), Feedback Thought in Social Science and System Theory, University of Pennsylvania Press, Philadelphia, PA.

Richmond, B. (1991). Systems Thinking. Four Key Questions. Watkinsville, GA: High Performance Systems, available at: http://www.imarpe.pe/imarpe/archivos/imarpe_ST\%204\%20Key\%20Questions.pdf

Richmond, B. (1993). Systems Thinking: Critical Thinking Skills for the 1990s and beyond. System Dynamics Review, Vol. 9 No. 2, pp. 113-133.

Richmond, B. (2000), The “Thinking” in Systems Thinking, Pegasus Communications, Waltham, MA.

Roberts, N. (1978), Teaching dynamic feedback systems thinking: an elementary view", Management Science, Vol. 24 No. 8, pp. 836-843.

Royce\&Associates. (2019). The Butterfly Effect: Everything You Need to Know About This Powerful Mental Model, available at: https://fs.blog/2017/08/the-butterfly-effect/

Senge, P.M. (1990 first ed.; 2006 last ed.). The Fifth Discipline: The Art and Practice of the learning Organization, NewYork: Doubleday/Currency.

Senge, P.M. et al. (1994). The Fifth Discipline Fiel The Fifth Discipline Fieldbook, Nicholas Brealey Paperback Edition.

Sterman, J.D. (1994). Learning in and about complex systems, System Dynamics Review, Vol. 10 No. 23, pp. 291-330.

Sterman J.D. 2000. Business Dynamics: Systems Thinking and Modeling for a Complex World. McGraw-Hill Education.

Stevie, S. (2008). Frog In A Pot, available at: https://www.youtube.com/watch?v=svpsLZDgFK4. 
Swanson J. (2002). Business Dynamics. Systems Thinking and Modeling for a Complex World, Journal of the Operational Research Society, Vol. 53 No. 4, pp. 472- 473.

Teal \& Co. (2016). The Frog in Boiling Water: The Myth and the Metaphor, available at: http://tealandco.com/the-frog-in-boiling-water-the-myth-and-the-metaphor/

Tithof, C. (2016). The Law of Accelerating Returns, available at: https://www.unit4.com/blog/2016/09/the-law-ofaccelerating-returns

Turing, A. (1950). Computing Machinery and Intelligence, Mind, Vol. 59 No. 236, pp. 433-60, available at:http://www.abelard.org/turpap/turpap.htm.

von Bertalanffy, V.L. (1968), General System Theory: Foundations, Development, Applications, George Braziller, New York, NY.

Von Foerster, H. (1984). Principles of self-organization in a socio-managerial context. In: Ulrich, H., Probst, G.J.B. (Eds.), Self-Organization and Management of Social Systems. Springer, Berlin, pp. 2-24.

von Foerster, H. (1991). Ethics and Second-Order Cybernetics, available at: http://ada.evergreen.edu/ arunc/texts/cybernetics/heinz/ethics.pdf.

von Foerster, H. (2003), Understanding understanding: Essays on cybernetics and cognition. New York, Berlin: Springer Verlag, available at: https://www.pangaro.com/Heinz-von-Foerster/Heinz_Von_Foerster-Understanding_Understanding.pdf.

Wikipedia (2018). Boiling frog, available at:https://en.wikipedia.org/wiki/Boiling_frog.

Wikipedia (2019). EffettoFarfalla (Butterfly effect), available at: https://it.wikipedia.org/wiki/Effetto_farfalla. Wright, D. and Meadows, D.H. (2012), Thinking in Systems: A Primer, Taylor and Francis, Abingdon, Oxfordshire.

Yang - Li, Chuanhong -Xu (2013). Study on the Ecological MICE Model Based on System Dynamics. International Journal of Business and Social Science, Vol. 4 No. 14, pp. 239-247. 